\title{
What Can Cash Shortfalls and Windfalls Tell Us About Finance Constraints?
}

Toni M. Whited*

University of Wisconsin, Madison

May 20, 2008

${ }^{*}$ Corresponding author. School of Business, University of Wisconsin, Madison, WI 53706-1323. 608-262-6508. twhited@bus.wisc.edu. We are grateful for helpful comments from seminar participants at Columbia University. 


\title{
What Can Cash Shortfalls and Windfalls Tell us about Finance Constraints
}

\begin{abstract}
This paper addresses whether agruably exogenous shocks to pension assets examines the relative magnitude of financial versus real frictions by looking at how firms react to quasi-exogenous cash shortfalls. To answer the question theoretically, we examine a dynamic model of financing and exogenous cash shortfalls. We find that when financing costs are high, firms adjust on real margins and vice versa. We find that firms optimally avoid costly cash shortfalls, only experiencing these events after serious negative shocks to profits. We also find that commonly used regression tests for the presence of finance constraints can produce false positives. In contrast, regression discontinuity techniques can provide an accurate method for uncovering the existence and magnitudes of finance constraints.
\end{abstract}




\section{Introduction}

Dating back at least to the work of Gurley and Shaw (1955) and extending to modern treatments of this question, as in, for example, Bernanke and Gertler (1988) and Hennessy and Whited (2007), most research has concentrated on the existence and magnitude of financial frictions. However, firms also suffer from a variety of real frictions, such as regulatory distortions, sluggish price responses arising from imperfect competition, and costs of adjusting the capital stock. This question is important because its answer has implications for the transmission of monetary policy and for understanding whether corporate financial policies affect real firm outcomes.

If financial frictions are to affect real economic activity, they must be at least as important as real frictions. This paper examines the relative magnitude of these costs on a microeconomic level, examining which sets of costs are bigger for which firms. Two broad options are available for approaching this question empirically: structural estimation of a dynamic model or reduced form estimation. This paper takes the less ambitious approach of reduced form estimation and asks how firms react to "exogenous" shocks to their resource base. The basic underlying hypothesis is that firms will adjust on the least costly margins when their resources are stretched.

Dating back to the influential work of Fazzari, Hubbard, and Petersen (1988), researchers have used the sensitivity of investment to cash flow as a metric for gauging the severity of finance constraints. The intuition behind this test is straightforward. If a firm cannot obtain outside finance, then its investment should respond strongly to movements in internal funds. Implementing this idea requires controlling for investment opportunities; otherwise, cash flow might capture movements in investment opportunities instead of movements in internal funds. An enormous literature that examines regressions of investment on a proxy for investment opportunities (usually Tobin's q) and cash flow. Surveyed in Hubbard (1998) and Stein (2003), this body of work almost always finds that the sensitivity of investment to cash flow is higher for a priori constrained firms.

More recently, two strands of the literature have questioned both the existence and the meaning of these findings. For example, Erickson and Whited (2000) find that cash flow sensitivity is an 
artifact of measurement error in $q$, and that correcting for this measurement error leaves no cash flow sensitivity at all for any groups of firms. Even if cash flow sensitivity exists, a variety of theoretical models have questioned its meaning. Gomes (2001) attributes cash flow sensitivity in part to

In an intriguing recent article, Rauh (2006) uses as exogenous shocks the contributions firms are required to make to their defined benefit pension plans if assets backing these plans fall below the estimated liabilities. Although the contributions themselves are clearly endogenously determined with other real and financial firm decisions, the contributions are calculated via a rule that entails a discrete shock to firm resources if the firm's pension assets fall below its pension liabilities. One can exploit this discontinuity to deal with the endogeneity problem. In so doing, Rauh (2006) (Rauh, hereafter) find that firms cut their capital expenditures almost 70 cents for every dollar of mandatory pension contributions. The finding is important because it demonstrates that external finance is more costly than internal finance. However, the finding is also puzzling inasmuch as firms do face substantial costs of adjusting both the capital stock and the rate of investment.. For example, Cooper and Haltiwanger (2006) estimate that the former are economically important on a microeconomic basis, and Christiano, Eichenbaum, and Evans (2005) demonstrate that the latter are important for explaining aggregate business cycle dynamics. The findings in Rauh are therefore perplexing because it seems plausible that firms would prefer to adjust assets and liabilities with low adjustment costs.

This article argues that this puzzle can be explained. We build on the ingenious insight of Rauh of using pension contributions, but we refine the econometric methodology he uses and, accordingly, find strikingly different results. In particular, we find firms tend to adjust on financial margins rather than real margins when hit with shocks. In general, they cut distributions to shareholders, draw down accumulated cash balances, and tap sources of external finance. Although small firms have a stronger tendency to adjust on real margins than large firms, the small firms do not alter capital expenditures. Instead, they liquidate inventories and cut employment.

To better understand the approach used in this paper, it is important to elaborate on the work- 
ings of defined benefit (DB) pension plans. Companies with DB pension plans promise employees a specific monthly benefit at retirement. Typically this benefit is calculated based on employee salary and service, and government rules state that firms must make contributions to their pension plans to be able to meet these future pension liabilities. If the market value of these contributions (pension assets) exceeds the expected future pension liabilities, the pension plan is considered to be overfunded. Conversely, if the value of the pension assets is less than the pension liabilities the plan is considered to be underfunded. If the pension plan is overfunded the firm is free to contribute to the plan, although contributions above a specified ceiling receive unfavorable tax treatment. If the firm withdraws funds from its pension funds, it can be subject to severe excise taxes. On the other hand, if the plan is underfunded the firm is required to contribute more funds to its pension plan. These mandatory pension contributions (MPC's) are determined according to a government rule that is a complicated nonlinear function of the funding gap (the difference between pension assets and liabilities).

If firms experience funding gaps, they do not have much leeway to play with pension liabilities. First, companies rarely change the amount of benefits promised to their employees. Second, restrictive rules govern the actuarial assumptions companies can make with regard to their liabilities. Third, although the pension liabilities change depending on the interest rate environment, these changes are dwarfed by the changes in the market value of pension assets that are due to fluctuations in the value of the investment portfolio. In summary, fluctuations in the funding gap (and consequently MPCs) are for the most part driven by how much companies contribute to their plans and how the invested pension assets perform.

Because the firm chooses whether or not to fund its pension plan, the decision of whether to pay a future MPC is made jointly with investment and financing choices. Consequently, the financial shocks (MPCs) in this setting are endogenous. However, because the function that links underfunding to MPCs has kinks and discontinuities, Rauh argues that "the sharp nonlinearities of pension funding requirements, particularly around the threshold of underfunding, allow for the identification of an effect of required contributions on investment that is purged of this endogeneity 
problem." Intuitively, firms on each side of the kink are not much different from one another on the dimension of funding status, and they can be thought of as randomly assigned to paying the MPC or not.

Although Rauh discusses identification around the kinks in the function relating MPCs and underfunding, he includes the whole sample in his estimation. Because this function is public knowledge, firms optimize subject to the existence of these discontinuities and endogenously choose whether they want to be close to point of a funding violation. That firms actively manage and anticipate future MPCs is vividly illustrated in this quote from Ford Motor Company's 2005 10K form:

"In 2005, we made $\$ 2.5$ billion of cash contributions to our funded pension plans. During 2006, we expect to contribute $\$ 1.5$ billion to our worldwide pension plans. . .Based on current assumptions and regulations, we do not expect to have a legal requirement to fund our major U.S. pension plans in 2006."

Clearly, Ford is planning its contributions in 2005 and 2006 to avoid having to face unanticipated financial shocks in 2006.

As a consequence of this endogeneity, once the data analyst considers violations away from the discontinuity, it becomes more difficult to identify the effect of the financial shock on firm real and financial decisions. One can make assumptions, discussed in Van der Klaauw (2002) and delineated below, under which a "global" analysis produces the same results as a "local" analysis.

We deal with this endogeneity problem in two ways. First, we use a dynamic model to better understand when using a full sample regression provides the same answers as a purely local regression around a discontinuity. The model features a firm with an infinite horizon and a stochastic production technology that employs both factors that are costless and costly to adjust. This firm is burdened with an inherited pension plan subject to MPCs, its pension assets are subject to random shocks to value, and it can only raise external finance at a premium to the opportunity cost of internal funds. It chooses external finance, fixed and variable factors, distributions, and pension 
contributions endogenously. In this setting we find that firms do optimally anticipate and overfund their pension liabilities. Further, we find that misleading results can be produced by testing for the effects of MPCs on firm decisions using firm-year observations away from the point of a funding violation. In particular, we find that one can find a response of real decisions even when external finance is costless. Finally, we find that using a local analysis around the discontinuity point is a more informative and accurate method. More specifically, our paper fits into the prior literature that has tried to understand the relation between finance and investment by studying how firms respond to arguably exogenous shocks to cash flow. Clearly, Rauh fits into this category. In addition, Blanchard, Lopez-de-Silanes, and Shleifer (1994) study legal settlements; and Lamont (1997) studies the reaction of the non-oil subsidiaries of oil firms to the dramatic drop in oil prices in the mid-1980s. One difference between this paper and these other three is their exclusive focus on the sensitivity of investment to cash flow. In contrast, we seek to look at a much broader question: the relative magnitude of financial and real frictions. Finally, our paper is most closely related to Chava and Roberts (2007), who also use a local discontinuity analysis to examine the effects of bond covenant violations on corporate investment.

This paper proceeds as follow. Section 2 introduces the econometric methodology. Section 3 describes the model, the simulation procedure, and its results. Section 4 describes the data; Section 5 presents the results, and Section 6 concludes.

\section{Empirical Strategy}

We wish to identify the margins on which firms respond to changes in their resource base. The main empirical challenge is finding a source of independent variation in internal funds. To this end we borrow the useful and novel insight in Rauh that one can use mandatory pension contributions, even though they are clearly endogenously determined with other firm decisions. The key institutional feature of these contributions that allows identification is that they occur when a continuous variable, net pension assets, falls below zero.

To see how this discontinuity aids in identification, it is useful to consider an ideal experimental 
setting in which one would flip a coin to assign a pension funding violation to a group of firms at random and then compare treated and control groups. Clearly, this sort of experiment is infeasible, but one can obtain a quasi-experimental setting because the firms that have barely violated the pension funding rules are not much different from those that have barely escaped a violation. Therefore, the near-escapees and near-violators can be thought of as close-to-randomly assigned to a violation, and by calculating the average differences between characteristics of these two groups of firms, one can estimate what is called a local average treatment effect, or LATE. This idea of regression discontinuity is originally from Thistlethwaite and Campbell (1960).

More formally, let $y_{i}$ be a variable of interest, such as investment, employment, liquid assets, or external financing. Let $w_{i}$ be a violation indicator, and let $s_{i}$ be the funding surplus as a fraction of pension liabilities. We are interested in estimating the regression

$$
\begin{aligned}
& y_{i}=\beta+\alpha w_{i}+u_{i} \\
& w_{i}=w\left(s_{i}\right)=1\left\{s_{i} \leq 0\right\},
\end{aligned}
$$

in which $\alpha$ is the average treatment effect from "treatment" with a funding violation. If were were to try estimating this on a sample of firms with wide variation in funding surpluses and deficits, assignment is not random; so $E\left(u_{i} \mid w_{i}\right) \neq 0$, and OLS produces biased coefficients.

As we have argued informally, however, we can use a restricted sample to estimate a LATE, which we define formally as

$$
L A T E=\lim _{s \downarrow 0} E(y \mid s)-\lim _{s \uparrow 0} E(y \mid s) .
$$

Why does this expression identify the treatment effect, $\alpha$ ? To see why, note from (1) that

$$
\begin{aligned}
\lim _{s \downarrow 0} E(y \mid s)-\lim _{s \uparrow 0} E(y \mid s) & =\alpha\left(\lim _{s \downarrow 0} E(w \mid s)-\lim _{s \uparrow 0} E(w \mid s)\right)+\lim _{s \downarrow 0} E(u \mid s)-\lim _{s \uparrow 0} E(u \mid s) \\
& =\alpha(1-0)+\lim _{s \downarrow 0} E(u \mid s)-\lim _{s \uparrow 0} E(u \mid s)
\end{aligned}
$$

If we assume that $E(u \mid s)$ is continuous in $s$, then the last term goes to zero and we have

$$
\alpha=\lim _{s \downarrow 0} E(y \mid s)-\lim _{s \uparrow 0} E(y \mid s) .
$$


The assumption that $E(u \mid s)$ is continuous in $s$ crucial, and it is therefore important to understand what it means in economic terms. If one takes the regression (1) seriously, it implies that the only variable that should determine firm investment or employment or external financing or any other variable we consider is whether a firm's pension assets are greater than its pension liabilities. This interpretation is, of course, absurd, but it points out that many determinants of our variables of interest are omitted from (1) and are therefore implicitly contained in the error term, $u_{i}$. The continuity assumption then implies that none of these variables exhibits a discontinuity at the exact point of a pension funding violation. This assumption is from an intuitive standpoint likely to hold because it is hard to imagine that a variable such as Tobin's $q$ would jump down at the point of a pension funding violation.

One difficulty with estimating a LATE is that one cannot necessarily extrapolate one's inferences to the rest of the sample. It is possible to do so, however, by using the concept of a control function from Heckman and Robb (1985). Suppose that the only determinant of a pension funding violation is the difference between pension assets and liabilities. Then one can write the regression error, $u_{i}$, as

$$
u_{i}=E\left(u_{i} \mid s_{i}\right)+e_{i}
$$

in which $e_{i}$ is, by definition, orthogonal to $w_{i}=w\left(s_{i}\right)$. Substituting (3) into (1) then gives

$$
\begin{aligned}
y_{i} & =\beta+\alpha w\left(s_{i}\right)+E\left(u_{i} \mid s_{i}\right)+e_{i} \\
& =\beta+\alpha w\left(s_{i}\right)+k\left(s_{i}\right)+e_{i}
\end{aligned}
$$

in which $k\left(s_{i}\right) \equiv E\left(u_{i} \mid s_{i}\right)$. In general, $k\left(s_{i}\right)$ will be a smooth function of $s_{i}$, although it will only be linear if $u_{i} \mid s_{i}$ is normally distributed, which is an implausible assumption in this instance. For example, investment is highly skewed. Nonetheless, if we are willing to swallow the assumption that $s_{i}$ is the only determinant of $w_{i}$, we can estimate this regression by including smooth functions of the distance between pension assets and pension liabilities in the regression.

Clearly, this assumption is hard to swallow, but thinking about the assumption points out the key difficulty with estimating (4) on a sample with wide variation in pension funding status. The 
regression must be very well specified in order for this technique to work. If not, then if $w\left(s_{i}\right)$ is correlated with anything that is left out of the regression, its coefficient will be biased. Van der Klauuw (2002) puts the point slightly differently by noting that estimating (4) requires strong assumptions to achieve identification. In particular, one has to assume that the effects of $s_{i}$ (the pension funding gap) on $y_{i}$ are adequately controlled for by other variables in the regression.

This condition may be violated for a variety of reasons. For example, if $y_{i}$ is the rate of investment, then the regression (4) should contain a measure of investment opportunities. As pointed out in Erickson and Whited (2000), the usual measure of investment opportunities, Tobin's $q$, only captures about fifty percent of the variation in true investment opportunities. Even if one corrects for measurement error, reduced form investment regressions only explain about half of the variation in investment. In the cases of employment, firm-level data on average wages are unavailable in our data source (Compustat); so any employment demand equation that will be seriously misspecified. In terms of the other variables we consider-cash, equity issuance, short term debt issuance, long-term debt issuance, inventories, dividends, and share repurchases - it is highly likely that any of these variables and the funding gap respond to unobserved demand or technology shocks. This problem renders it even more difficult to specify an appropriate regression.

We tackle the uncertainty surrounding the correct specification of (4) in two ways. First, we use simulation of an economic model to determine if estimating (4) in a large sample produces erroneous results. In our empirical work, we avoid these difficulties by estimating the LATE given by $(2)$.

\section{A Model of Pension Funding}

To motivate our empirical work and to determine if our empirical strategy is appropriate, we consider a discrete-time, infinite-horizon, partial-equilibrium model of a firm. First we describe technology and financing. Then we move on to a description of the model calibration and the simulation results. 


\subsection{Technology and Financing}

A risk-neutral firm uses capital, $k$, and variable factors of production, $l$, to produce output, and it faces a combination demand and productivity shock, $z$. The firm's per period profit function is given by $\pi(k, l, z)$. It is continuous, with $\pi(0,0, z)=0, \pi_{z}(k, l, z)>0, \pi_{k}(k, l, z)>0$, and $\pi_{l}(k, l, z)>0$. Also, the Hessian with respect to $k$ and $l$ is negative definite and the usual Inada conditions hold. Concavity of $\pi(k, l, z)$ results from decreasing returns in production, a downward sloping demand curve, or both. The shock $z$ is observed by the producer before he makes his current period decisions. It takes values in $[\underline{z}, \bar{z}]$ and follows a first-order Markov process with transition probability $g\left(z^{\prime}, z\right)$, in which a prime indicates a variable in the next period; $g\left(z^{\prime}, z\right)$ has the Feller property. Labor is paid a real wage of $w$ each period.

Without loss of generality, $l$ and $k$ lie in a compact set. Each period the firm sets an optimal level of $l$ so that $\pi_{l}(k, l, z)=w$. The Inada conditions ensures that any optimal level of $l$ lies in a compact set with a maximum of $\bar{l}$. As in Gomes (2001), define $\bar{k}$ as

$$
\pi(\bar{k}, \bar{l} ., \bar{z})-d \bar{k} \equiv 0
$$

in which $d$ is the capital depreciation rate, $0<d<1$. Concavity of $\pi(k, l, z)$ and the Inada conditions ensure that $\bar{k}$ is well-defined. Because $k>\bar{k}$ is not economically profitable, $k$ lies in the interval $[0, \bar{k}]$. Compactness of the state space and continuity of $\pi(k, z)$ ensure that $\pi(k, z)$ is bounded.

Investment, $I$, is defined as

$$
I \equiv k^{\prime}-(1-d) k
$$

The firm purchases and sells capital at a price of 1 and incurs adjustment costs that are given by

$$
A\left(k, k^{\prime}\right)=c k \Phi_{i}
$$

For simplicity, $A\left(k, k^{\prime}\right)$ contains only a fixed component, $c k \Phi_{i}$, in which $c$ is a constant, and $\Phi_{i}$ equals 1 if investment is nonzero, and 0 otherwise. The fixed cost is proportional to the capital stock so that the firm has no incentive to grow out of the fixed cost. ${ }^{1}$ We omit a smooth adjustment

\footnotetext{
${ }^{1}$ Replacing $c k$ with a fixed number, $F$, changes the analysis little because the capital stock is bounded.
} 
cost because curvature of the profit function acts to smooth investment over time in the same way that quadratic adjustment costs do.

The firm inherits a pension liability, $b$, and must hold assets, $p$, to counter the liability. These assets earn a stochastic rate of return, $r$, that follows a first order Markov process with transition probability $f\left(r^{\prime}, r\right)$. If $p(1+r)$ falls below $b$, then the firm must make a contribution to $p$ equal to $(b-p)$. This provision restricts the choice set for $p$. The firm must also pay a lump-sum excise tax of $\tau$. To make the choice set compact, we assume an arbitrarily high upper bound on assets, $\bar{p}$. This upper bound is imposed without loss of generality because our assumption of a stochastic rate of return ensures bounded saving.

For simplicity all external finance takes the form of equity. To preserve tractability, we do not model costs of external equity as the outcome of an asymmetric information problem. Instead, we capture adverse selection costs and underwriting fees in a reduced-form fashion. Accordingly, we define equity issuance/distributions as

$e\left(k, k^{\prime}, p, p^{\prime}, l, z, r\right) \equiv e \equiv \pi(k, l, z)+p(1+r)-p^{\prime}-w l-\left(k^{\prime}-(1-d) k\right)-A\left(k, k^{\prime}\right)-(b-p(1+r)+\tau) \Phi_{b}$,

in which $\Phi_{b}$ equals one if $p(1+r)-b<0$. If $e>0$, the firm is making distributions to shareholders, and if $e<0$, the firm is issuing equity. For simplicity, the external equity-cost function is linear

$$
\begin{gathered}
\phi(e) \equiv \Phi_{e} \lambda e \\
\lambda \geq 0
\end{gathered}
$$

in which $\Phi_{e}$ equals 1 if $e<0$, and 0 otherwise.

The firm chooses $\left(k^{\prime}, p^{\prime}, l\right)$ each period to maximize the value of expected future cash flows, discounting at the risk-free interest rate, $\delta$. The Bellman equation for the problem is

$$
V(k, p, z, r)=\max _{k^{\prime}, p^{\prime}, l}\left\{\begin{array}{c}
\pi(k, l, z)+p(1+r)-p^{\prime}-w l-\left(k^{\prime}-(1-d) k\right)-A\left(k, k^{\prime}\right)+\phi(e)+ \\
\frac{1}{1+\delta} \iint V\left(k^{\prime}, p^{\prime}, z^{\prime}, r^{\prime}\right) d g\left(z^{\prime}, z\right) d f\left(r^{\prime}, r\right)
\end{array}\right\}
$$

The first seven terms represent the excess of cash inflows over cash outflows and the third term represents the continuation value of the firm. The model satisfies the conditions for Theorem 9.6 
in Stokey and Lucas (1989), which guarantees a solution for (9). Theorem 9.8 in Stokey and Lucas (1989) ensures a unique optimal policy function, $\left\{k^{\prime}, p^{\prime}\right\}=h(k, l, p, z, r)$, because the functional form chosen for $\phi(e)$ ensures that $e+\phi(e)$ is weakly concave in its first two arguments.

\section{Simulations}

We solve the model numerically and investigate its implications for reduced-form regressions via simulation. We first describe the parameterization of our baseline simulation and explain the properties of optimal firm behavior. We then explain the experiments we perform on the model and the results of these experiments.

\subsection{Model Calibration}

The profit function is given by $\pi(k, z)=z k^{\theta} l^{\eta-\theta}$, in which we set $\theta$ to 0.7 and $\eta$ to 0.175 , which correspond to the estimates of labor's share and mark-ups from Rotemberg and Woodford (1992, 1999). We set the risk-free interest rate, $\delta$, equal to $4 \%$, which lies between the values chosen by Hennessy and Whited (2007) and Gomes (2001). We set the wage equal to 1.

To specify a stochastic process for the shock $z$, we follow Gomes (2001) and assume that $z$ follows an $A R(1)$ in logs,

$$
\ln \left(z^{\prime}\right)=\rho_{z} \ln (z)+v_{z}^{\prime}
$$

in which $v^{\prime} \sim N\left(0, \sigma_{v}^{2}\right)$. Our baseline parameter choices for $\rho$ and $\sigma_{v}$ are the averages of the estimates of these two parameters in Hennessy and Whited (2005): the serial correlation of the shock, $\rho$, is set at 0.66 and the standard deviation of the shock, $\sigma_{v}$, is set at 0.121 . The stochastic return on pension assets is assumed to be i.i.d. with a mean of $4 \%$ and a standard deviation of $20 \%$. In this risk-neutral setting the mean of the shock equals the risk-free rate, and the standard deviation is set approximately equal to the standard deviation of the S\&P500 index.

We follow Hennessy and Whited (2005) to parameterize the financing function, setting $\lambda_{1}=$

0.059. To set the size of the pension liabilities, $b$, we first compute the steady-state labor force from a version of this model with no pension fund, and then compute the pension liability as this 
steady-state labor force times the following quantity: one third of the real wage in perpetuity, discounted at the risk-free rate, starting in 20 time periods.

To find values for the adjustment cost parameter, $c$, we turn to Cooper and Haltiwanger (2006), who estimate $c=0.039$. We set the depreciation rate equal to 0.15 , a figure approximately equal to the average in our data of the ratio of depreciation to the net capital stock.

Finally, to find a numerical solution we need to specify a finite state space for the three state variables. We let the capital stock lie on the points

$$
\left[\bar{k}(1-d)^{40}, \ldots, \bar{k}(1-d)^{1 / 2}, \bar{k}\right]
$$

We let the productivity shock have 25 points of support, transforming (10) into a discrete-state Markov chain using the method in Tauchen (1986). We let $p$ have 40 equally spaced points in the interval $[0, \bar{p}]$, in which $\bar{p}$ is set to $\bar{k} / 2$. The optimal choice of $p$ never hits this upper bound.

We solve the model via iteration on the Bellman equation, which produces the value function $V(k, p, z, r)$ and the policy function $\left\{k^{\prime}, l^{\prime}, p^{\prime}\right\}=h(k, p, z, r)$. In the subsequent model simulation, the spaces for $z$ and $r$ are expanded to include 100 points, with interpolation used to find corresponding values of $V, k, l$, and $p$. The model simulation proceeds by taking a random draw from distribution of $\left(z^{\prime}, r^{\prime}\right)$ (conditional on $z$ and $r$ ), and then computing $V(k, p, z, r)$ and $h(k, p, z, r)$. We use these computations to generate an artificial panel of firms by simulating the model for 10,000 identical firms over 200 time periods, keeping only the last 20 observations for each firm.

\subsection{Simulation Results}

Knowledge of $h$ and $V$ also allows us to compute interesting quantities such as cash flow, Tobin's $q$, mandatory contributions, and distributions. Specifically, we define our variables to mimic the sorts of variables used in the literature.

\begin{tabular}{ll}
\hline Ratio of investment to the "book value" of assets & $\left(k^{\prime}-(1-d) k\right) / k$ \\
Ratio of cash flow to the book value of assets & $(z \pi(k, l)-w l) / k$ \\
Tobin's $q$ & $(V(k, p, z, r)+p-b) / k$ \\
Ratio of equity issuance to the book value of assets & $-\min (0, e) / k$ \\
Ratio of mandatory contributions to the book value of assets & $-\min (0, p(1+r)-b) / k$ \\
Ratio of the optimal funding gap to the book value of assets & $(p-b) / k$ \\
Ratio of the realized funding gap to the book value of assets & $(p(1+r)-b) / k$ \\
\hline
\end{tabular}


As discussed by Erickson and Whited (2000), computation of average $q$ using real-world data sets involves numerous judgment calls and imputations. Of course, these problems produce measurement error. In contrast, there is no measurement error when average $q$ is computed from a structural model. Because it is impossible to remove measurement error from the real-world data, for some of our simulations we put the model on equal footing by adding a pseudo-normal error term, denoted $u$, to model-generated $q$. We set $\sigma_{u}=2.4$. The implied $R^{2}$ from the regression of $(V+p-b) / k+u$ on $(V+p-b) / k$ is approximately 0.4 - a figure in line with the estimates in Erickson and Whited (2000).

Figure 1 depicts a histogram of the optimal ratios of $(p-b) / k$ for our simulated panel. This figure represents the gap between pension assets and pension liabilities before the firms are hit with the shocks $r$. The most striking feature of this figure is the tiny fraction of firm/year observations in which the firm finds it optimal to have a small funding surplus. Clearly firms anticipate the possibility that they will have to make mandatory contributions, and they therefore build a cushion to insure against this possibility. This cushion is usually sizeable, with most firms holding assets whose value is between $20 \%$ and $35 \%$ of the capital stock. When they do choose to have a small funding surplus, it happens when they have had a series of high positive productivity shocks.

Figure 2 depicts a similar histogram of the realized ratios $(p(1+r)-b)$ for our simulated panel after the firms are hit with the shocks $r$. Approximately $4 \%$ of the firm-year observations end up with a negative funding gap, and some of these gaps are quite sizeable, amounting to as much as $20 \%$ of the capital stock.

Figure 3 portrays the coefficient $\alpha_{2}$ in the following regression, which is from Rauh.

$\frac{k^{\prime}-(1-d) k}{k}=\alpha_{0}+\beta \frac{V(k, p, z, r)+p-b}{k}+\alpha_{1} \frac{z \pi(k, l)-w l}{k}+\alpha_{2} \frac{-\min (0, p(1+r)-b)}{k}+\alpha_{3} \frac{p-b}{k}+u$.

The left side variable is the rate of investment. The regressors are Tobin's $q$, cash flow, mandatory contributions, and the funding gap. Recall that Rauh claims that this coefficient on mandatory 
contributions measures the response of investment to an exogenous resource shortfall. ${ }^{2}$ Panel A of Figure 3 plot the coefficient, $\alpha_{2}$ as a function of the parameter describing the cost of external finance, $\lambda$, and the parameter describing the cost of adjusting the capital stock, $c$. Each graph is constructed by running 10 simulations, each with a different value for the parameter of interest, and then by interpolating between the points. The response of investment to mandatory contributions is negative, thus supporting the basic empirical results in Rauh. Further, it increases in absolute value with the cost of external finance and decreases in absolute value with the cost of adjusting the capital stock. The economic interpretation of these results, however, is complex, especially in light of our next result that investment responds to mandatory contributions even when external finance is costless. This surprising result, however, occurs because (11) is an arbitrary regression specification that only approximates the highly nonlinear first order conditions for optimal investment. Therefore, the term corresponding to mandatory contributions picks up the effect of fundamental investment opportunities in addition to the effect of the cost of external finance.

Panel B examines the coefficient on mandatory contributions in a regression exactly analogous to (11), except that the left hand side variable is $\left(l^{\prime}-l\right) / k$. The response of the change in employment to mandatory contributions closely resembles the response of investment. It become more negative as the cost of external finance increases and less negative as the cost of adjusting the capital stock increases. However, the interesting pattern here is the markedly higher coefficient on mandatory contributions for any configuration of financial and adjustment costs. This result makes sense because in this model labor is costless to adjust. In light of this costless adjustment, it is at first counter intuitive that labor becomes less responsive to mandatory contributions as the cost of adjusting the capital stock rises. However, the firm's technology constrains the range of the optimal mix of capital and labor. Therefore, although labor always adjusts more than the capital stock, it also inherits some of the sluggishness of the capital stock when adjustment costs rise.

The two main take-away points from this figure can be summarized as follows. First, the regression (11), although informative about the cost of external finance, is not perfectly specified,

\footnotetext{
${ }^{2}$ We have also tried subtracting optional pension contributions $\left(p^{\prime}-p\right)$ from the cash flow term. We find very similar results.
} 
and can allow the inference of costly external finance even when external finance is costless. Second, the firm adjusts on the least costly margin.

We have also studied two other margins on which the firm adjusts: whether it ever uses external finance and whether it over-funds its pension assets after an adverse shock. The answer to both questions is a resounding yes. If we replace the left-hand-side variable in (11) with $e / k$, we find large negative coefficients on mandatory contributions that are about twice as large in absolute value as the coefficients depicted in Panel B. Although this response decreases slightly when the cost of external finance rises, it always remains stronger than the response of either labor or capital. Why does the firm adjust more on a financial margin than on a real margin? If a firm alters its factor inputs, its productivity and revenues change over a long horizon. In contrast, if the firm has to tap external finance, it pays a one-time fee that has a much smaller impact on its long-run value.

To examine the over-funding question, we replace the left-hand-side variable in (11) with a variable that is zero if the firm is not making mandatory contributions and that is otherwise the difference between actual and mandatory contributions. In this case we find a large positive coefficient that rises with the cost of external finance. This result mirrors the histogram in Figure 1. Firms anticipate having to make mandatory contributions and build cushions to protect themselves from this event.

The impact of inserting measurement error in $(V(k, p, z, r)+p-b) / k$ into these regressions is large. For all of these regressions and for all underlying parameter values, the coefficients on mandatory contributions rise by a factor of three to five in absolute value. This result makes sense because mandatory contributions and $(V(k, p, z, r)+p-b) / k$ are highly negatively correlated, and because the effect of measurement error in one variable impacts the coefficients on other variables via their covariances. One important lesson can be gleaned from this result. If the underlying regression is poorly specified, then examining the impact of mandatory contributions on factor demand may result in misleadingly large estimated effects.

We next examine whether using regression discontinuity can do a better job of detecting real and financial frictions. To this end we isolate those simulated observations that have a funding 
gap or surplus that is less than one percent of the value of pension liabilities. Figure 4 depicts the local response of real decisions - labor and capital - to moving from a small funding surplus to a small funding deficit. First, for both labor and capital, there is no local response if external finance is costless. This result stands in contrast to results from examining the regression (11), and it indicates that looking at local responses can be a more accurate method for detecting costly external finance. Second, and not surprisingly, capital and labor decrease more sharply as external finance becomes more costly and less sharply, if at all, as investment adjustment costs rise. The monotonic relation between external finance and real adjustment also lends credence to examining local responses.

Figure 5 illustrates the local response of financial decisions - cash and external financing - to moving from a small surplus to a small funding deficit. First, if external finance is costless, the firm finances the entirety of the funding gap with external sources. The firm also uses some of the proceeds from this external financing to overfund the pension assets so as to avoid paying a lump sum deficit penalty in the future. As the cost of external finance rises, this behavior is attenuated but not erased. Even if the firm only gets to keep 70 cents of every dollar of external finance raised, it still uses this source of funds rather than cutting its factors of production. The intuition, again, is that this one-time fee, although large, is not as large as the long-run cost of decreasing factors of production. Second, as the cost of adjusting the capital stock rises, the firm's financial responses to crossing the line from a surplus to a deficit rise. The firm is essentially substituting financial flexibility for the decrease in real flexibility.

\section{Conclusion}

This paper has sought to find out how firms react to exogenous cash shortfalls. On a purely theoretical basis, one would expect them to adjust on the margins that entail the fewest costs. Indeed, this intuition is confirmed in a model in which firms are subject to random cash shortfalls that arise because of the existence of an inherited pension plan that requires funding. We find that when financing costs are high, firms adjust on real margins and vice versa. This model also 
demonstrates that firms anticipate the probability of a shortfall by building a buffer stock of liquid assets to counteract the shock. Therefore, firms that do experience shortfalls do so when they after a particularly bad productivity shock. In sum, our model tells us that the relative magnitude of real versus financial adjustments is an empirical question and that one must be careful to account for the endogeneity of these shortfalls.

To answer the question empirically, we use a regression discontinuity design, in which the discontinuity is the point of violation of underfunding of corporate defined benefit pension plans. We examine firm-year observations in which the firm's pension assets are just barely less than its pension liabilities, and in which, consequently, the firm must make a mandatory contribution to its pension plan. We compare this group to a control group of firm-year observations in which the firm has just barely escaped having to make a mandatory contribution. In this quasi-experimental setting, we find little evidence that firms cut back on their real activities such as employment and investment. Instead, they use a variety of financial tools, such as cash, working capital management, and short-term external financing to fund their pension liabilities. This evidence suggests that in the sample we consider financial adjustment costs are much less substantial than real adjustment costs. Further work to examine this question on a broader scale would be interesting. 


\section{References}

Bernanke, Ben S. and Mark Gertler, 1988, Agency costs, net worth, and business fluctuations, American Economic Review 79, 14-31.

Blanchard, Olivier Jean, Florencio Lopez-de-Silanes, and Andrei Shleifer, 1994, What do firms do with cash windfalls, Journal of Financial Economics 36, 337-360.

Chava, Sudheer and Michael R. Roberts, 2007, How does financing impact investment? The role of debt covenants, Journal of Finance, forthcoming.

Christiano, Lawrence J., Martin Eichenbaum, and Charles L. Evans, 2005, Nominal rigidities and the dynamic effects of a shock to monetary policy, Journal of Political Economy 113, 1-45.

Cooper, Russell and John Haltiwanger, 2006, On the nature of capital adjustment costs, Review of Economic Studies 73, 611-633.

Erickson, Timothy and Toni M. Whited, 2000, Measurement error and the relationship between investment and q, Journal of Political Economy 108, 1027-57.

Fazzari, Steven, R. Glenn Hubbard, and Bruce Petersen, 1988, Financing constraints and corporate investment, Brookings Papers on Economic Activity 1, 144-195.

Gomes, Joao, 2001, Financing investment, American Economic Review 91, 1263-1285.

Gurley, J. and Shaw, E., 1955, Financial aspects of economic development, American Economic Review 45, 515-538.

Heckman, James J. and Richard Robb, 1985, Alternative methods for evaluating the impact of interventions, in J. Heckman and B. Singer eds., Longitudinal Analysis of Labor Market Data, Cambridge: Cambridge University Press.

Hennessy, Christopher A. and Toni M. Whited, 2005, Debt dynamics. Journal of Finance 60, 1129-1165.

Hennessy, Christopher A. and Toni M. Whited, 2007, How costly is external financing? Evidence from a structural estimation, Journal of Finance 62, 1705-1745

Hoxby, Caroline, 2000, The effect of class size on student achievement: New evidence from population variation, Quarterly Journal of Economics 115, 1239-1285.

Lamont, Owen, 1997, Cash flow and investment: evidence from internal capital markets, Journal of Finance 52, 83-109.

Munnell, Alicia, and Mauricio Soto, 2003, The outlook for pension contributions and profits, Working Paper, Fifth Annual Conference of the Retirement Research Consortium.

Rauh, Joshua, 2006, Investment and financing constraints: evidence from the funding of corporate pension plans, Journal of Finance 61, 33-71

Rotemberg, Julio J. and Michael Woodford, 1992, Oligopolistic pricing and the effects of aggregate demand on economic activity, Journal of Political Economy 100, 1153-1207.

Rotemberg, Julio J. and Michael Woodford, 1999, The cyclical behavior of prices and costs. In: Taylor, J. B., Woodford, M. (Eds.), Handbook of Macroeconomics, Vol. 1B. North Holland, Amsterdam, pp. 1051-1135. 
Silverman, Bernard, 1986, Density Estimation for Statistics and Data Analysis, Monographs on Statistics and Applied Probability Volume: 26, (Chapman and Hall, London).

Stein, Jeremy, 2003, Agency, information and corporate investment, Handbook of the Economics of Finance, G.M. Constantinides, M.Harris and R.Stulz (eds.), Elsevier Science, 109-163.

Stokey, Nancy L. and Robert E. Lucas, 1989, Recursive Methods in Economic Dynamics. Harvard University Press, Cambridge, Mass. and London.

Tauchen, George, 1986, Finite state Markov-chain approximations to univariate and vector autoregressions, Economics Letters 20, 177-181.

Thistlethwaite, D., and D. Campbell, 1960, Regression-discontinuity analysis: An alternative to the ex post facto experiment, Journal of Educational Psychology 51, 309-317.

Van der Klaauw, Wilbert, 2002, Estimating the effect of financial aid offers on college enrollment: A regression-discontinuity approach, International Economic Review 43, 1249-1287 
Figure 1: Optimal Simulated Funding Surpluses

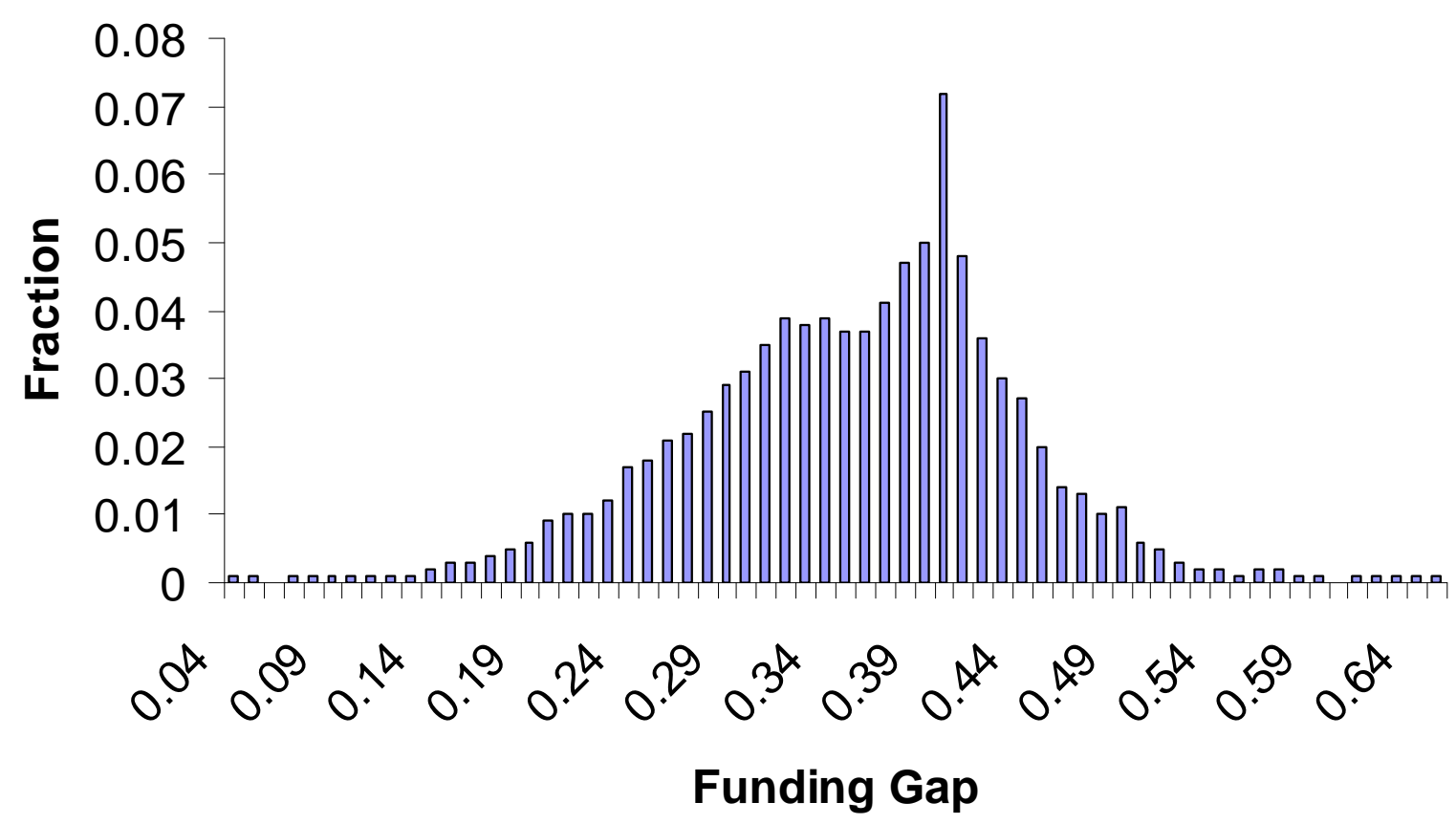

This figure depicts a histogram of optimal funding surpluses, as a fraction of the capital stock, chosen by the baseline simulated firms. 
Figure 2: Realized Simulated Funding Surpluses and Deficits

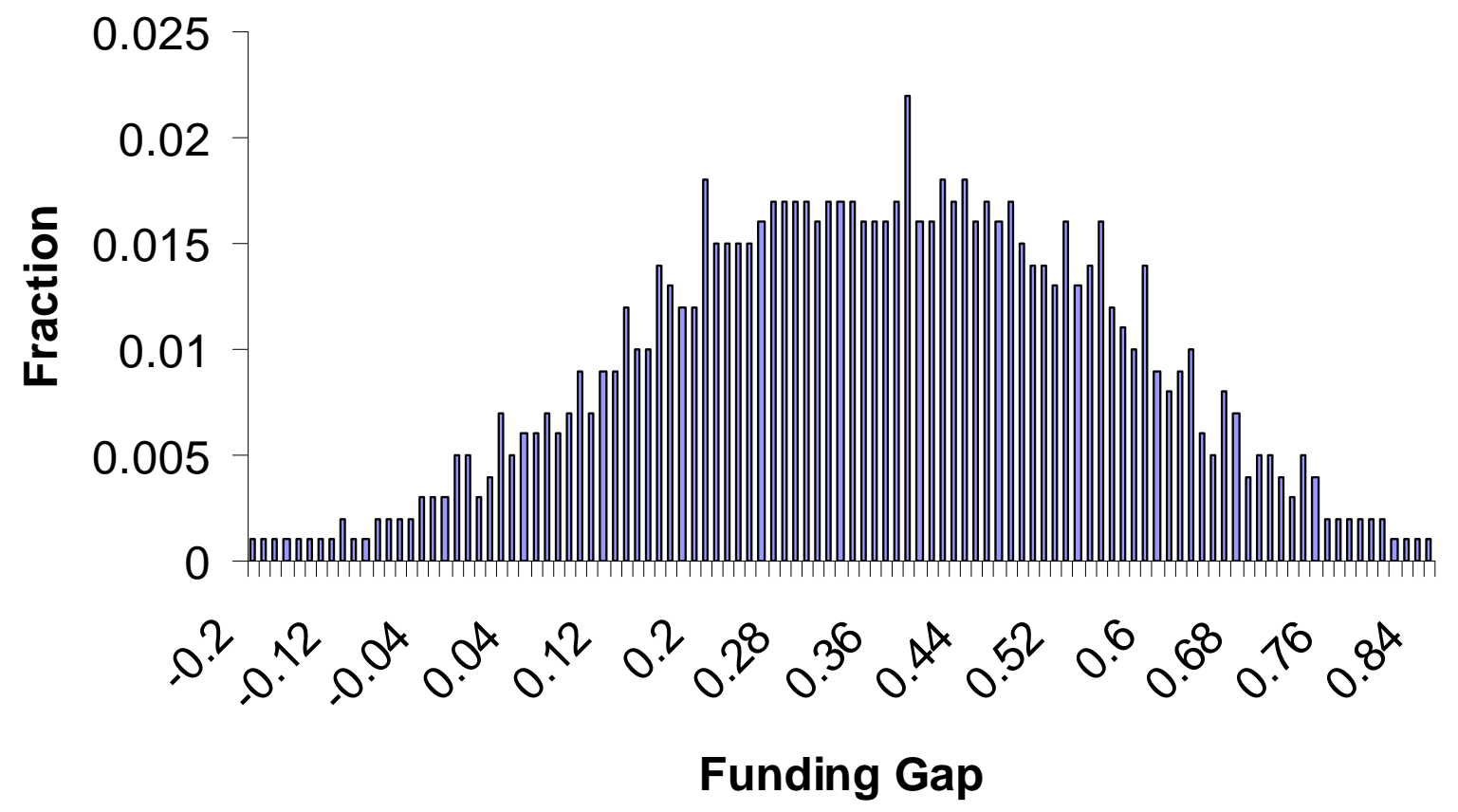

This figure depicts a histogram of realized funding surpluses and deficits, as a fraction of the capital stock, after the baseline simulated firms are hit with a shock. 
Figure 3: Factor Sensitivity to Mandatory Contributions

Panel A: Investment Regressions
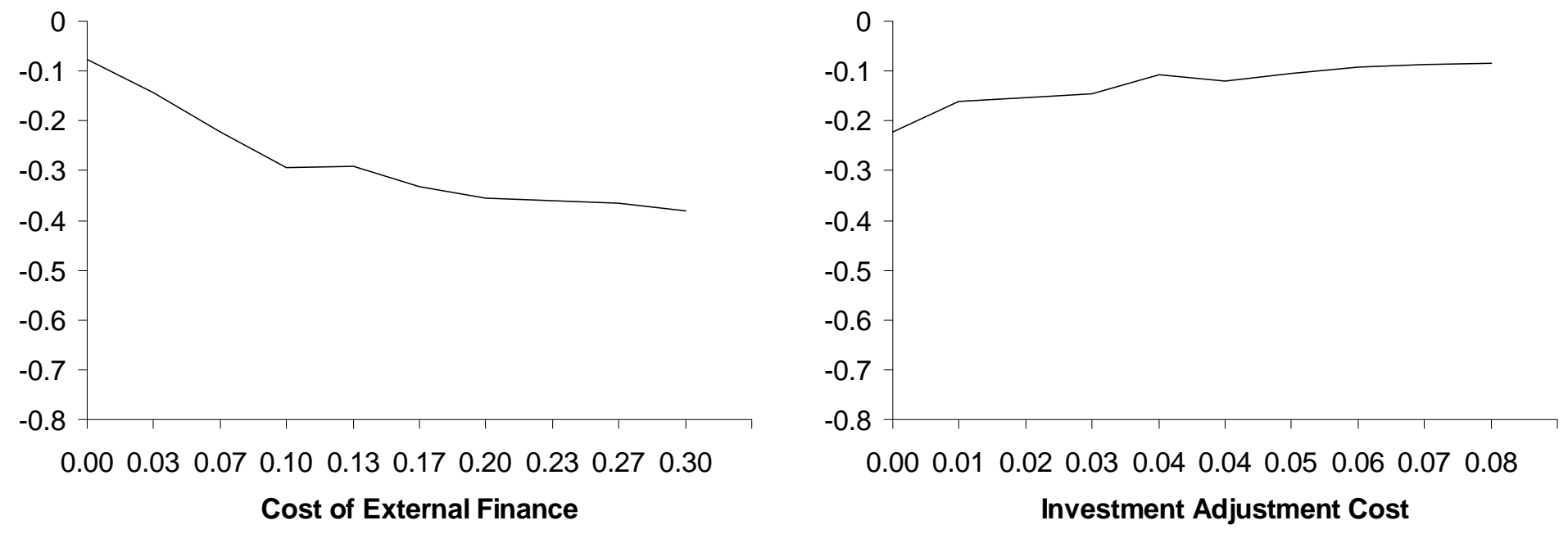

Panel B: Labor Change Regressions
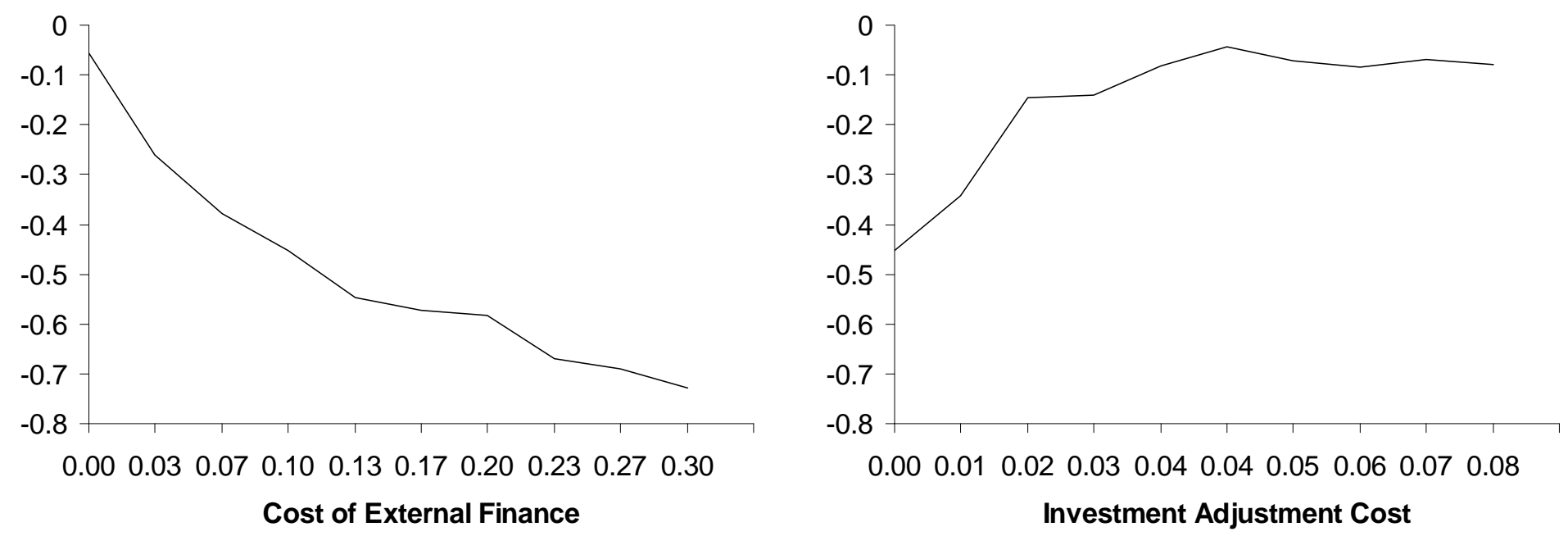

This figure depicts the coefficient $\alpha_{2}$ in the regression

$$
\frac{X}{k}=\alpha_{0}+\beta \frac{V(k, p, z, r)+p-b}{k}+\alpha_{1} \frac{z \pi(k, l)-w l}{k}+\alpha_{2} \frac{-\min (0, p(1+r)-b)}{k}+\alpha_{3} \frac{p-b}{k}+u .
$$

In Panel A $X \equiv k^{\prime}-(1-d) k$, and in Panel $\mathrm{B} X \equiv l^{\prime}-l$. 
Figure 4: Local Response of Real Decisions to Funding Violations

Panel A: Investment
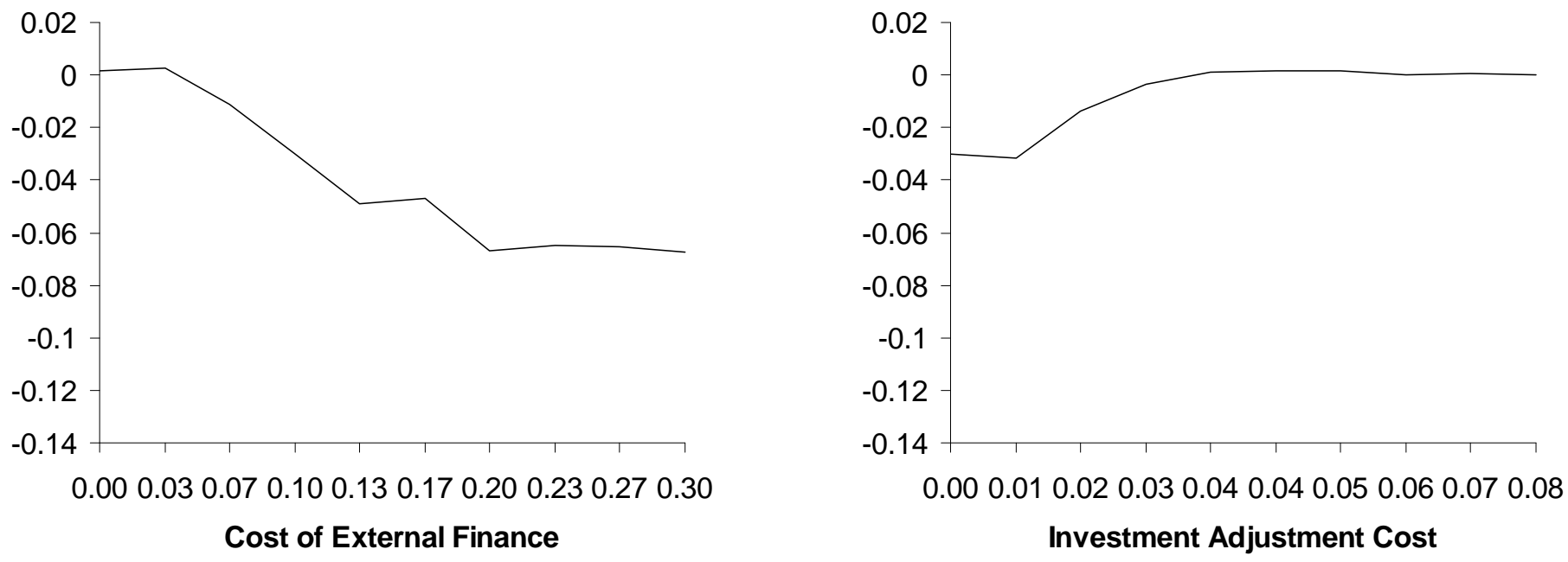

Panel B: Labor Change
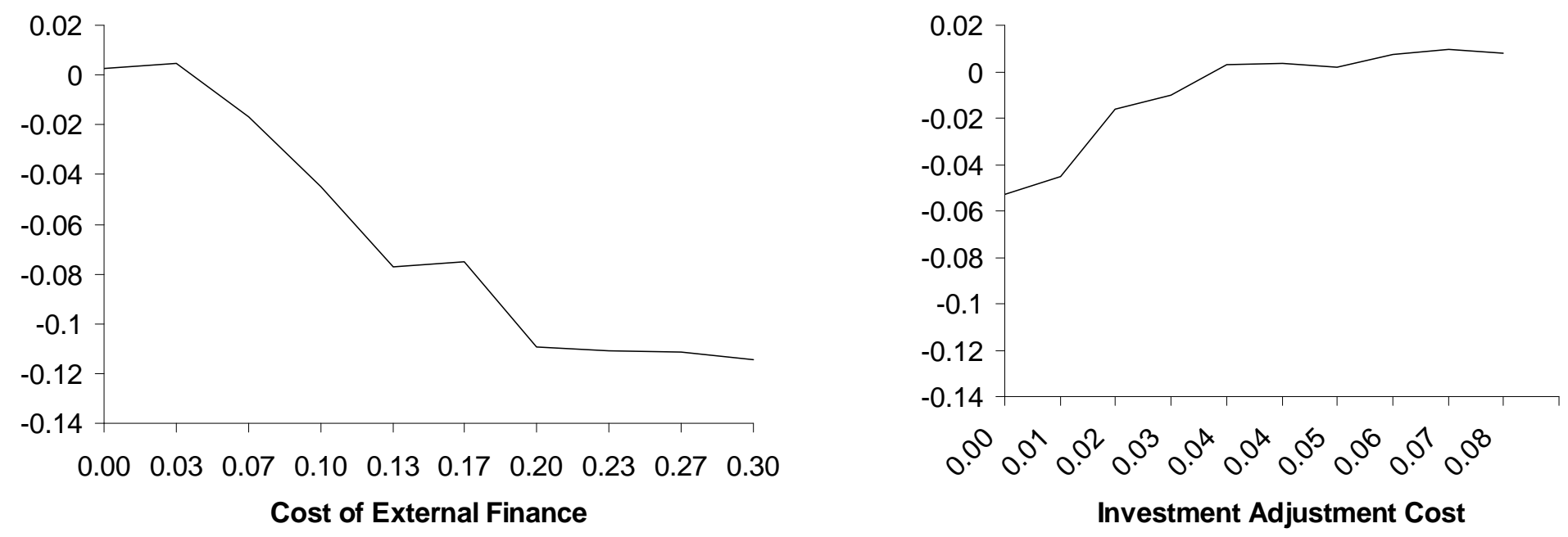

This figure compares the average investment and average employment changes for firms that have funding surpluses no greater than one percent of liabilities to the same quantities for firms that have funding deficits no greater than one percent of liabilities. 
Figure 5: Local Response of Financial Decisions to Funding Violations

Panel 1: Cash
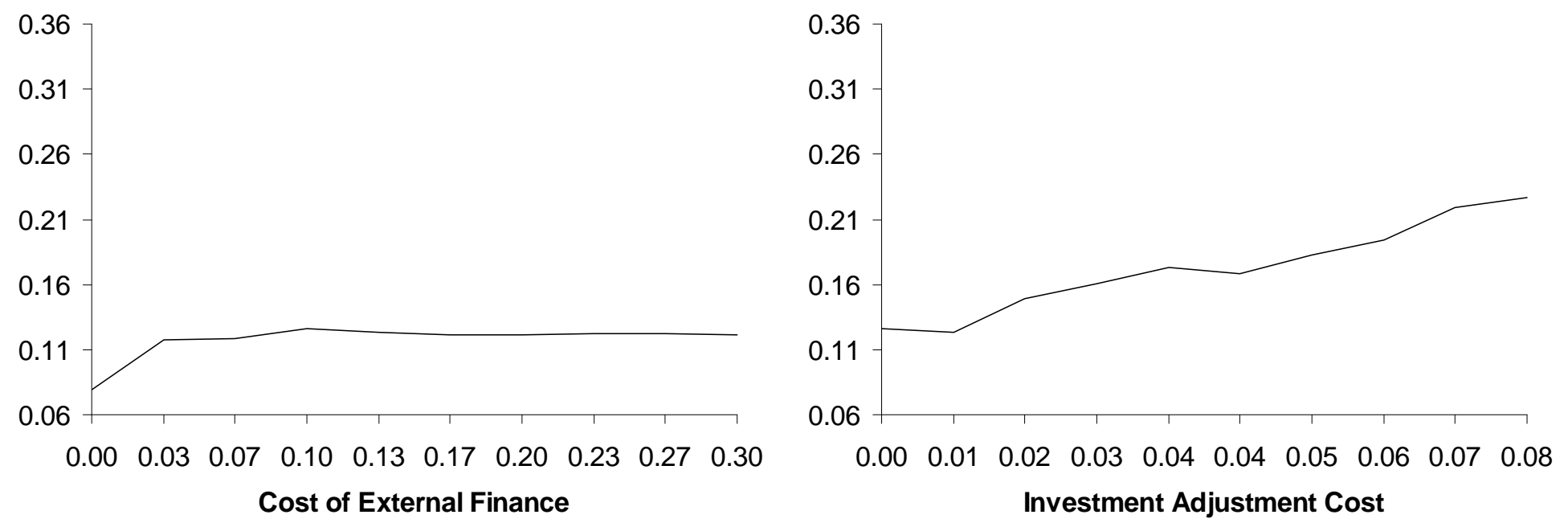

Panel B: External Finance
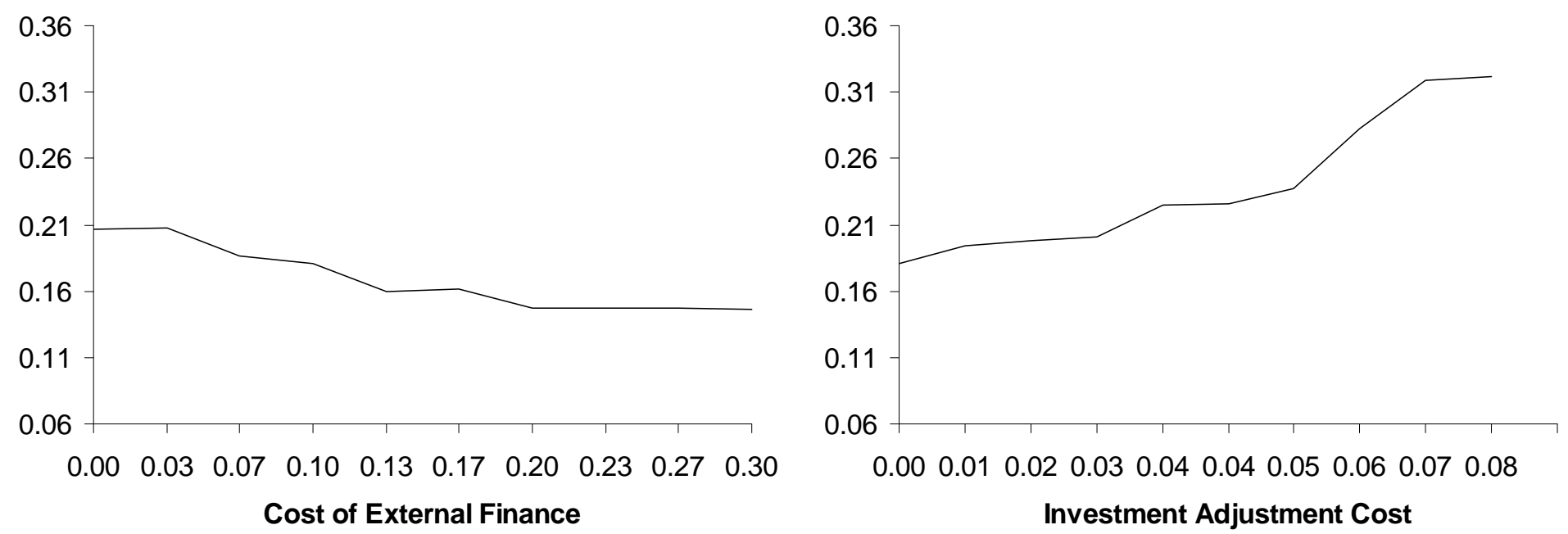

This figure compares the average pension assets and average external financing for firms that have funding surpluses no greater than one percent of liabilities to the same quantities for firms that have funding deficits no greater than one percent of liabilities. 